\title{
Influência do clima nas hospitalizações por asma em crianças e adolescentes residentes em Belo Horizonte, Minas Gerais, Brasil
}

\author{
The influence of climatic conditions on hospital admissions for \\ asthma in children and adolescents living in Belo Horizonte, Minas \\ Gerais, Brazil
}

Cláudia Silva Dias (https://orcid.org/0000-0002-1205-8862) ${ }^{1}$

Sueli Aparecida Mingoti (https://orcid.org/0000-0003-3416-4014) ${ }^{2}$

Ana Paula Romanelli Ceolin (https://orcid.org/0000-0002-9237-0804) ${ }^{3}$

Maria Angélica de Salles Dias (https://orcid.org/0000-0002-1891-0585) ${ }^{3}$

Amélia Augusta de Lima Friche (https://orcid.org/0000-0002-2463-0539) ${ }^{3}$

Waleska Teixeira Caiaffa (https://orcid.org/0000-0001-5043-4980) ${ }^{3}$
${ }^{1}$ Pontifícia Universidade Católica de Minas Gerais. Av. Dom José Gaspar 500, Coração Eucarístico. 30535610 Belo Horizonte MG Brasil. claudiadiaspuc

@yahoo.com.br

${ }^{2}$ Departamento de Estatística, Instituto de Ciências Exatas, Universidade Federal de Minas Gerais (UFMG). Belo Horizonte MG Brasil. ${ }^{3}$ Observatório de Saúde Urbana, Faculdade de Medicina, UFMG. Belo Horizonte MG Brasil.

\begin{abstract}
Limited research exists on the influence of climatic conditions on the risk of hospital admission for asthma in Minas Gerais, Brazil. The objectives of this article are: a) to evaluate the influence of climatic conditions on hospital admissions for asthma and lower respiratory tract infections (LRTIs) among children and adolescents living in Belo Horizonte during the period 2002 to 2012 and identify epidemic peaks of admissions for asthma; $b$ ) to compare local seasonal patterns of admissions for asthma and LRTIs. Using hospital admission data stratified by aged group, regression analysis was performed to determine the relationship between the variables. Epidemic peaks were identified using an ARIMA model. There was an increase in admissions for asthma with an increase in relative humidity after rainy periods; admissions for bronchiolitis were associated with low levels of maximum temperature and rainfall. Rainy periods can lead to an increase in indoor and outdoor humidity, facilitating fungal proliferation, while cold periods can lead to an increase in the spread of viruses.

Key words Hospital admissions for asthma, Climate, Hospital admissions for Bronchiolitis, Child and Adolescent
\end{abstract}

Resumo O risco de hospitalização por asma influenciado pelo disparo das condições climáticas é pouco explorado em Minas Gerais. Os objetivos deste artigo são: a) avaliar a influência dos fatores climáticos nas hospitalizações por asma e por infecções virais do trato respiratório inferior (IVTRI), de 2002 a 2012, em crianças e adolescentes residentes em Belo Horizonte (BH) e estimar períodos epidêmicos para as hospitalizações por asma; b) comparar o padrão sazonal local das hospitalizações por asma e IVTRI. Utilizando as hospitalizações por asma estratificadas $e$ por bronquiolite de 0-4 anos, a partir das guias de Internação Hospitalar, modelos estatísticos de regressão foram aplicados para avaliar o relacionamento entre as variáveis. Para estimar períodos epidêmicos foi utilizado o modelo de séries temporais da classe ARIMA. Foi observado um incremento nas hospitalizações por asma com aumento da umidade relativa no período pós-chuvas, as hospitalizações por bronquiolite se associaram a baixos niveis de temperatura máxima e precipitação. Períodos mais chuvosos podem propiciar o aumento da umidade outdoor e indoor favorecendo proliferação fúngica. Já os períodos mais frios podem favorecer o aumento da disseminação de virus.

Palavras-chave Hospitalização por asma, Clima, Hospitalização por Bronquiolite, Criança e adolescente 


\section{Introdução}

A asma caracteriza-se por inflamação crônica, hiper-responsividade brônquica e limitação variável ao fluxo aéreo, reversível espontaneamente ou com broncodilatadores. A sua determinação é marcada por uma miríade de fatores ${ }^{1,2}$.

No Brasil, mesmo com a queda no número de hospitalizações, a asma ocupa o terceiro maior custo financeiro do Sistema Único de Saúde (SUS) nesta categoria ${ }^{3}$. Apesar de estudos comprovarem redução das hospitalizações em Minas Gerais $^{4}$ e Belo Horizonte $(\mathrm{BH})^{5}$, a queda em BH tem sido menos impactante para populações residentes em áreas mais vulneráveis à saúde, caracterizadas como vilas e favelas ${ }^{6}$, remetendo ao caráter de iniquidade deste agravo em saúde.

De acordo com o Nacional Heart, Lung, and Blood Institute são vários os fatores que propiciam e interagem na exacerbação da asma. São fatores ligados às características dos indivíduos e estilos de vida e também relacionados ao ambiente, tais como infecções virais do trato respiratório inferior (IVTRI), contato com alérgenos indoor e outdoor e mudanças meteorológicas ${ }^{2,7,8}$. Ressalta-se que todos os fatores são potencialmente mediados pela condição socioeconômica ${ }^{2}$.

Os vírus respiratórios têm sido reconhecidos como importantes no crescimento acentuado dos episódios de sibilância e exacerbação por asma, principalmente em crianças com idade inferior a dois anos. O vírus sincicial respiratório (VSR) é reconhecido como um dos maiores responsáveis pelos episódios de sibilância nessas crianças?.

Outro importante fator relacionado ao disparo da crise asmática em pessoas suscetíveis é o efeito do clima. Estudos conduzidos em diferentes regiões do mundo, inclusive do Brasil, têm encontrado associação entre hospitalizações por asma e estações climáticas ${ }^{10-12}$. Entretanto, o papel dos fatores meteorológicos (temperatura, precipitação acumulada e umidade relativa) no mecanismo da indução e/ou agravamento da asma ainda não é claro em nosso meio.

No inverno, o aumento do ar frio pode comprometer a função pulmonar em pacientes com asma e induzir broncoespasmo ${ }^{13}$. Também, períodos com menos horas de sol e mais chuvosos propiciam o aumento da umidade intradomiciliar, a proliferação fúngica, a aglomeração dos residentes e a transmissibilidade viral ${ }^{14,15}$. Ainda, as emissões de gases de efeito estufa aceleram o aquecimento global e com isso elevam a temperatura no inverno e na primavera, causando antecipação e aumento do período de polinização das plantas. A concentração dos esporos alérgenos circulantes favorecem os níveis de poluentes, trabalhando em sinergismo na determinação da difusão e agregação dos gases na atmosfera ${ }^{7}$. Tudo isso pode ocasionar aumento da exposição humana a esses gases, podendo induzir a crise de asma e o aumento da suscetibilidade de indivíduos predispostos ${ }^{15}$.

Sabendo que a interação entre o clima e a saúde é específica em relação à localização geográfica, compreender os padrões sazonais locais e os gatilhos ambientais associados se faz importante, notadamente em áreas geográficas nas quais estudos desta natureza com um largo período de investigação, não foram encontrados.

Diante disso, os objetivos do estudo foram: a) avaliar a influência dos fatores climáticos (temperaturas máxima e mínima, precipitação acumulada e umidade relativa) nas hospitalizações por asma e por infecções virais do trato respiratório inferior em crianças e adolescentes residentes em BH, no período de 2002 a 2012, e estimar períodos epidêmicos para hospitalização por asma; b) comparar o padrão sazonal local das hospitalizações por asma e IVTRI em BH no mesmo período.

Os achados do presente estudo poderão contribuir no manejo da asma, nos programas de prevenção e de cuidados de saúde para este agravo, além da melhor alocação da atenção e recursos durante os períodos epidêmicos, com o intuito de mitigar o agravamento da doença e consequente hospitalização.

A inclusão da bronquiolite viral, neste estudo, permitirá a análise do comportamento desta doença associado às mudanças climáticas, nas crianças de 0-4 anos, entendendo que muitas vezes a criança apresenta sintomas comuns da asma. Observar o comportamento de ambas poderá trazer uma confirmação diagnóstica mesmo em crianças abaixo de 4 anos.

\section{Material e método}

Foi realizado estudo observacional descritivo e de séries temporais, na cidade de Belo Horizonte, Minas Gerais, no período de 2002 a 2012.

Belo Horizonte (BH), capital do estado de Minas Gerais, está situada na região Sudeste do Brasil e possui população de 2.375.151 habitantes, área de $331,4 \mathrm{~km}^{2}$, com densidade populacional de 7.167,02 habitantes $/ \mathrm{km}^{2}$. Possui altitude média de 900 metros, latitude de $19,9^{\circ} \mathrm{S}$ e longitude de $43,9^{\circ} \mathrm{W}^{16}$. 


\section{Hospitalizações por asma}

Foram obtidas por meio das guias de Autorização de Internação Hospitalar (AIH), emitidas pelos hospitais e fornecidas pela Secretaria Municipal de Saúde de Belo Horizonte (SMSA/ $\mathrm{PBH}$ ). Para este estudo, todas as hospitalizações com diagnóstico principal de asma a partir da Classificação Internacional de Doenças (CID-10) - J45 a J46 - em crianças e adolescentes de 0 a 14 anos, que residiam em Belo Horizonte e internaram em hospitais públicos e/ou conveniados com o Sistema Único de Saúde de Belo Horizonte (SUS-BH) foram incluídas. As hospitalizações foram categorizadas nas seguintes faixas etárias: 0-4, 5-9 e 10-14 anos.

\section{Infecções virais do trato respiratório inferior (IVTRI)}

A fonte de informações utilizada para obter as taxas de hospitalizações por bronquiolite de crianças de 0 a 4 anos, que residiam em $\mathrm{BH}$ e internaram em hospitais conveniados ao SUS-BH, também foi a AIH. Abrangeu os códigos J21, J21.0, J21.8 e J21.9 como diagnóstico principal da CID-10, no mesmo período ( $1^{\circ}$ de janeiro de 2002 a 31 de dezembro de 2012). A restrição à faixa etária de 0-4 anos deveu-se ao conhecimento prévio de que $98 \%$ das hospitalizações por bronquiolite registradas nas $\mathrm{AIH}$ ocorreram nesta faixa de idade, na cidade e no período estudado.

\section{Taxas de hospitalização por asma e bronquiolite}

Para o cálculo da taxa de hospitalização anual, foi aplicada a correção da população considerando-se a necessidade de conciliação demográfica, tendo em vista a omissão na enumeração do total de pessoas no Censo Demográfico do Instituto Brasileiro de Geografia e Estatística (IBGE) de $2010^{16}$. Essa omissão para menores de cinco anos foi da ordem de 15 a 16\% para meninos e meninas, respectivamente, e de $13 \%$ para os grupos etários de cinco a nove anos. Foi então apli-

cado um fator de correção uniforme equivalente a 14,6\% nessas faixas etárias.

Ademais, foi calculada a taxa média anual de crescimento com base nas modificações demográficas de acordo com áreas delimitadas, tais como cidade formal e vilas/favelas. Estimando-se a população-base de 2010 , a partir da população de 2000, calculou-se a taxa de crescimento da coorte no período intercensitário para a cidade ${ }^{17}$, possibilitando o cálculo anual da população. As taxas de hospitalização foram calculadas a partir do número de hospitalizações por mês e por ano, tanto para a asma como para a bronquiolite de acordo com os estratos etários em estudo.

\section{Informações meteorológicas}

Os dados meteorológicos da temperatura máxima e mínima $\left({ }^{\circ} \mathrm{C}\right)$, umidade relativa (\%) e precipitação acumulada ( $\mathrm{mm}$ ) foram disponibilizados pelo Laboratório de Climatologia da PUC Minas - TempoClima e Prefeitura de Belo Horizonte CMAR/COMDEC obtidos a partir da Estação Convencional de Belo Horizonte - MG (Organização Meteorológica Mundial OMM:83587) e pertencente ao Instituto Nacional de Meteorologia (INMET) ${ }^{18}$.

As informações foram obtidas para todos os meses (132 meses) durante os 11 anos. O presente estudo utilizou a média mensal destes dados, para todos os anos.

\section{Análise estatística}

\section{Análises descritivas}

Foram compostas pela descrição das taxas anuais de hospitalização por asma e bronquiolite estratificadas por faixa etária, além das médias mensais das variáveis meteorológicas e do número de hospitalizações por asma (0-14 anos) e bronquiolite (0-4 anos) ocorridas em $\mathrm{BH}$, de 2002 a 2012.

\section{Análise de correlação e regressão}

Utilizou-se a correlação linear de Pearson para avaliar a relação das taxas de hospitalização por asma e bronquite com os dados meteorológicos. Os efeitos das variáveis meteorológicas foram analisados por modelos de regressão de Poisson utilizando como variáveis dependentes as taxas de hospitalizações por asma de 0-14 e de 0-4 anos e as taxas de hospitalização por bronquiolite de 0-4 anos. Para avaliar possível efeito tardio das variáveis meteorológicas nas taxas de hospitalizações no modelo de Poisson, as variá- 
veis do clima foram regredidas de um e dois meses antes da data da hospitalização.

\section{Séries temporais}

Estudos de sazonalidade requerem abordagem de séries temporais. Para isto, modelos estatísticos Auto-Regressive Integrated Moving Average (ARIMA) ${ }^{19}$ foram empregados para capturar o comportamento de cada variável ao logo do tempo, em função dos seus valores passados. $\mathrm{O}$ modelo utilizado faz parte da classe ARIMA (p,$\mathrm{d}, \mathrm{q}) \times(\mathrm{P}, \mathrm{D}, \mathrm{Q})[\mathrm{S}]$, em que p é a ordem do processo auto-regressivo (AR), q é a ordem do processo média móvel (MA), d é o número de diferenças na série original, $\mathrm{P}$ é a ordem do processo AR- sazonal, Q é a ordem do processo MA - sazonal e D é o número de diferenças no processo sazonal ${ }^{19}$. Analisaram-se as tendências do número de hospitalizações para os anos de 2013, 2014 e 2015 e seus intervalos de confiança. As diferenças de ordem d e D são necessárias para eliminar tendências observadas na série temporal (simples e sazonal) transformando-as em séries estacionárias.

Foi também realizado um procedimento para validar o modelo, no qual previsões foram realizadas para os dados do número de hospitalizações por asma dos anos de 2011 e 2012 com o modelo estatístico ARIMA estimado sem essas observações. Para avaliação da capacidade preditiva do modelo utilizou-se o erro médio absoluto (EMA), que é a média dos erros absolutos de previsão, calculado através da equação:

$$
\mathrm{EMA}=\frac{\sum_{i=1}^{n}\left|y_{i o b s}-\hat{y}_{i}\right|}{n}
$$

em que $y_{\text {iobs }}$ é o número de hospitalizações observadas, $\hat{y}_{i}$ é o número de hospitalizações previstas pelo modelo ARIMA ajustado e n é o número de observações previstas, que nesse caso especificamente corresponde a 24 observações.

Os dados foram processados e analisados no software $R$, pacote estatístico STATA e sendo o nível de significância de 5\% utilizado para avaliar a significância estatística dos testes de hipóteses realizados.

O estudo teve a aprovação do Comitê de Ética em Pesquisa da Universidade Federal de Minas Gerais.

\section{Resultados}

\section{Taxas de hospitalizações por asma e bronquiolite}

No período do estudo ocorreram 32.978 hospitalizações por asma de crianças/adolescentes de 0-14 anos, sendo, 18.962 (57,5\%) do sexo masculino e $14.016(42,5 \%)$ do sexo feminino. As taxas de hospitalizações por faixa etária podem ser vistas na Tabela 1.

De acordo com a Tabela 1, a faixa etária que mais apresentou hospitalização por asma foi a de 0-4 anos (25.926), seguida da de 5-9 (5.817) e de 10-14 (1.235). Percebe-se também a redução da taxa de hospitalização, ao longo dos anos, para todos os estratos de faixa etária.

Já as taxas de hospitalizações por bronquiolite na faixa etária de 0-4 anos, diferentemente da asma, mostraram um aumento com o passar dos anos (Tabela 1).

Verificada a média mensal do número de hospitalizações por asma e bronquiolite, as mais altas para hospitalização por asma foram nos meses de março, abril e maio. Para a bronquiolite foram nos meses de maio, junho e julho (Tabela 2). A correlação de Pearson entre o número de hospitalizações por asma e bronquiolite, ambas para crianças de 0-4 anos, foi positiva e significativa a $5 \%$ de significância $(0,30, \mathrm{p}=0,001)$.

Observam-se também, na Tabela 2, duas estações climáticas bem definidas na cidade: chuvosa, caracterizada por aumento da umidade e temperatura mínima; e seca, com umidade relativa mais baixa. A temperatura máxima sofre pouca variação entre os períodos.

Ao analisar a inter-relação entre as variáveis meteorológicas por meio da correlação de Pearson observou-se, como esperado, correlações significativas (5\% de significância) entre temperatura máxima e temperatura mínima $(\mathrm{r}=0,83, \mathrm{p}$ $<0,01)$; umidade relativa e precipitação acumulada $(\mathrm{r}=0,68, \mathrm{p}<0,01)$, precipitação acumulada e temperatura mínima $(\mathrm{r}=0,55, \mathrm{p}<0,01)$, umidade relativa e temperatura mínima $(\mathrm{r}=0,45, \mathrm{p}$ $<0,01)$; precipitação acumulada e temperatura máxima $(\mathrm{r}=0,28, \mathrm{p}<0,01)$ e, finalmente, correlação muito fraca, negativa e não significativa entre temperatura máxima e umidade relativa $(-0,03, \mathrm{p}=0,76)$.

No modelo de regressão de Poisson das taxas de hospitalizações por asma e variáveis meteorológicas, observou-se que o incremento de $1 \mathrm{~mm}$ na precipitação correspondeu a um decréscimo de $1 \%$ na taxa de hospitalização por mês e, cada 
Tabela 1. Taxa anual de hospitalização por asma e bronquiolite estratificada por faixa etária no período de 2002 a $2012, \mathrm{em} \mathrm{BH}^{*}$.

\begin{tabular}{|c|c|c|c|c|c|c|c|c|}
\hline \multirow{4}{*}{ Ano } & \multicolumn{8}{|c|}{ Faixa Etária } \\
\hline & \multicolumn{4}{|c|}{$0-4$} & \multirow{2}{*}{\multicolumn{2}{|c|}{$\begin{array}{c}5-9 \\
\text { Asma }\end{array}$}} & \multirow{2}{*}{\multicolumn{2}{|c|}{$\begin{array}{l}\text { 10-14 } \\
\text { Asma }\end{array}$}} \\
\hline & \multicolumn{2}{|c|}{ Asma } & \multicolumn{2}{|c|}{ Bronquiolite } & & & & \\
\hline & No & Taxa & No & Taxa & No & Taxa & No & Taxa \\
\hline 2002 & 3.716 & 21,45 & 412 & 2,38 & 683 & 3,67 & 109 & 0,59 \\
\hline 2003 & 3.326 & 19,31 & 456 & 2,68 & 611 & 3,32 & 142 & 0,77 \\
\hline 2004 & 3.366 & 19,66 & 508 & 3,03 & 682 & 3,75 & 127 & 0,70 \\
\hline 2005 & 2.699 & 15,85 & 374 & 2,27 & 613 & 3,40 & 130 & 0,72 \\
\hline 2006 & 2.214 & 13,08 & 406 & 2,50 & 480 & 2,69 & 86 & 0,48 \\
\hline 2007 & 2.148 & 12,76 & 395 & 2,47 & 525 & 2,98 & 111 & 0,63 \\
\hline 2008 & 1.893 & 11,31 & 604 & 3,84 & 506 & 2,90 & 102 & 0,58 \\
\hline 2009 & 1.699 & 10,20 & 423 & 2,73 & 423 & 2,45 & 105 & 0,61 \\
\hline 2010 & 1.773 & 10,70 & 536 & 3,52 & 469 & 2,74 & 118 & 0,69 \\
\hline 2011 & 1.612 & 9,73 & 583 & 3,83 & 408 & 2,40 & 98 & 0,58 \\
\hline 2012 & 1.480 & 8,93 & 911 & 5,98 & 417 & 2,47 & 107 & 0,64 \\
\hline Total & 25.926 & & 5.608 & & 5.817 & & 1.235 & \\
\hline
\end{tabular}

* Taxa de hospitalização por 1.000 .

Tabela 2. Médias mensais das variáveis meteorológicas e do número de hospitalizações por asma (0-14 anos) e bronquiolite (0-4 anos) ocorridas em BH, de 2002 a 2012.

\begin{tabular}{llcccccc}
\hline & Asma & Bronquiolite & $\begin{array}{c}\text { Temperatura } \\
\text { máxima }\end{array}$ & $\begin{array}{c}\text { Temperatura } \\
\text { mínima }\end{array}$ & $\begin{array}{c}\text { Precipitação } \\
\text { acumulada }\end{array}$ & Umidade \\
\hline Período & OUT & 188 & 24 & 29 & 19 & 109 & 59 \\
Chuvoso & NOV & 176 & 24 & 28 & 19 & 255 & 68 \\
& DEZ & 165 & 22 & 28 & 20 & 403 & 71 \\
& JAN & 160 & 28 & 28 & 20 & 358 & 71 \\
& FEV & 270 & 25 & 29 & 20 & 176 & 66 \\
& MAR & 431 & 45 & 28 & 20 & 209 & 69 \\
Período & MBR & 338 & 44 & 28 & 20 & 184 & 67 \\
& Média & 247 & 30 & 28 & 20 & 242 & 67 \\
& JUI & 371 & 86 & 26 & 17 & 23 & 63 \\
& JUL & 260 & 71 & 25 & 16 & 11 & 62 \\
& AGO & 184 & 55 & 25 & 15 & 6 & 57 \\
& SET & 194 & 32 & 27 & 16 & 10 & 53 \\
& Média & 236 & 54 & 28 & 17 & 55 & 54 \\
\hline
\end{tabular}

incremento na unidade de umidade relativa correspondeu a um aumento de aproximadamente $5 \%$ na taxa de hospitalização por asma por mês. Os achados foram observados para ambos os estratos de faixa etária 0-14 e 0-4 anos (Tabela 3) e foram estatisticamente significativos a $5 \%$ de significância.

Para as hospitalizações por bronquiolite, de 0 a 4 anos, o aumento de $1^{\circ} \mathrm{C}$ na temperatura máxima correspondeu a um decréscimo de
$21 \%$ na taxa de hospitalização por mês e, cada incremento de $1 \mathrm{~mm}$ na unidade de precipitação correspondeu a um decréscimo de $1 \%$ na taxa de hospitalização por bronquiolite por mês (Tabela 3) sendo os resultados estatisticamente significativos a 5\% de significância.

Para investigar efeito tardio da mudança meteorológica e a taxa de hospitalização por asma foi analisado a correlação entre as taxas de hospitalizações por asma e as informações meteo- 
Tabela 3. Modelo final da associação das taxas de hospitalizações por asma e bronquiolite e variáveis climáticas, do período de 2002 a 2012 em BH.

\begin{tabular}{lccccc}
\hline \multicolumn{1}{c}{ Hospitalização } & Coeficiente & DP & p-valor & IC (95\%) \\
\hline Asma 0-14 anos & & & & & \\
$\quad$ Precipitação & 0,99 & 0,0003 & $<0,001$ & 0,997 & 0,998 \\
$\quad$ Umidade & 1,05 & 0,0060 & $<0,001$ & 1,037 & 1,063 \\
Asma 0-4 anos & & & & & \\
$\quad$ Precipitação & 0,99 & 0,0002 & $<0,001$ & 0,997 & 0,998 \\
$\quad$ Umidade & 1,05 & 0,0042 & $<0,001$ & 1,040 & 1,057 \\
Bronquiolite 0-4 anos & & & & & \\
$\quad$ Temperatura máxima & 0,79 & 0,0486 & $<0,001$ & 0,701 & 0,892 \\
$\quad$ Precipitação & 0,99 & 0,0005 & $<0,001$ & 0,997 & 0,999 \\
\hline
\end{tabular}

rológicas defasadas de um e de dois meses. Os resultados obtidos da correlação entre a umidade relativa ocorrida um e dois meses anteriores à hospitalização e as taxas de hospitalizações por asma, mostraram correlação significativa (a 5\% de significância) para um e dois meses de defasagem $(r=0,41$ e 0,50 respectivamente, $p<0,01)$ sugerindo um possível efeito em maior prazo. A temperatura mínima mais elevada também apresentou correlação positiva significativa (a $5 \%$ de significância) quando defasada em um e dois meses $(r=0,36$ e 0,48 respectivamente, $p<0,00)$ com as taxas de hospitalizações por asma.

Para testar o efeito da exposição da variação climática ocorrida um e dois meses anteriores às hospitalizações utilizou-se também a regressão de Poisson. Foi possível observar associação das taxas de hospitalizações e os valores médios de temperaturas máximas e mínimas, umidade relativa e precipitação acumulada medidos um e dois meses antes das hospitalizações. Considerando que a temperatura mínima é dependente da temperatura máxima, foi incluída no modelo uma nova variável, a amplitude, correspondente à diferença entre as médias de temperaturas máxima e mínima ocorridas no mês e, subsequentemente refeitas as análises com um e dois meses de defasagem.

Considerando a defasagem de um mês no modelo final, tanto para as hospitalizações por asma de 0-14 quanto de 0-4 anos, o aumento de $1 \mathrm{~mm}$ na precipitação causou queda de $1 \%$ nas taxas de hospitalizações por asma e o aumento de $1 \%$ na umidade causou aumento de $4 \%$ nas taxas de hospitalizações por asma. Para as taxas de hospitalizações por bronquiolite, permaneceram no modelo final a amplitude da temperatura e a precipitação, sendo que o acréscimo de $1 \mathrm{~mm}$ na precipitação levou a queda de $1 \%$ na taxa de hospitalização e o aumento de $1^{\circ} \mathrm{C}$ na amplitude da temperatura levou a queda de $24 \%$ nas taxas de hospitalizações por bronquiolite (Tabela 4). As associações encontradas nos modelos de Poisson para asma e bronquiolite foram significativas a $5 \%$ de significância.

$\mathrm{Na}$ análise referente à defasagem de dois meses, apenas o aumento da umidade relativa mostrou-se significativamente associada (a 5\% de significância) à queda de aproximadamente 3\% na taxa de hospitalização por asma. Para as bronquiolites, o aumento da amplitude correlacionou com redução de 19\% na taxa de hospitalização pela doença, ou seja, a queda da temperatura aumenta o risco da ocorrência do evento (Tabela 4 ), sendo esses resultados significativos a $5 \%$ de significância.

$\mathrm{Na}$ modelagem da série temporal do número de hospitalizações por asma (0-14 anos) o melhor modelo encontrado foi o ARIMA $(0,1,2)(2,0,2)$ [12] que leva em consideração o padrão sazonal de 12 meses.

Para validar o modelo, o número de hospitalizações por asma nos anos de 2011 e 2012 foi excluído e as previsões para esses anos foram realizadas por meio do modelo ARIMA $(0,1,2)(2,0,2)$ [12] ajustado sem essas observações. O valor do EMA foi igual ao número de 55,67 hospitalizações, sugerindo que o modelo proposto é adequado para predizer o número de eventos futuros tanto pontualmente quanto por intervalo de $95 \%$ de confiança para o número real de hospitalizações como pode ser visto na Figura 1. Esse valor de EMA é relativo ao período em que as previsões foram realizadas.

O referido modelo reafirma a sazonalidade do evento e o comportamento histórico da redução do número de hospitalização por asma nas crianças e adolescentes em $\mathrm{BH}$ para os próximos anos. 
Tabela 4. Modelo final, da análise de regressão de Poisson, da variação climática ocorrida um e dois meses anteriores à data das hospitalizações por asma e bronquiolite registradas no período de 2002 a 2012, em BH.

\begin{tabular}{|c|c|c|c|c|c|c|c|c|c|c|}
\hline \multirow{2}{*}{ Hospitalização } & \multicolumn{5}{|c|}{ Defasagem de 1 mês } & \multicolumn{5}{|c|}{ Defasagem de 2 meses } \\
\hline & Coef. & DP & p-valor & \multicolumn{2}{|c|}{ IC } & Coef. & DP & p-valor & \multicolumn{2}{|c|}{ IC (95\%) } \\
\hline Precipitação & 0,99 & 0,0004 & $<0,001$ & 0,998 & 0,999 & - & - & - & - & - \\
\hline Umidade & 1,04 & 0,0009 & $<0,001$ & 1,031 & 1,057 & 1,04 & 0,001 & 0,000 & 1,034 & 1,038 \\
\hline \multicolumn{11}{|l|}{ Asma 0-4 anos } \\
\hline Precipitação & 0,99 & 0,0002 & $<0,001$ & 0,998 & 0,999 & - & - & - & - & - \\
\hline Umidade & 1,04 & 0,0040 & $<0,001$ & 1,032 & 1,049 & 1,03 & 0,005 & 0,000 & 1,023 & 1,043 \\
\hline \multicolumn{11}{|l|}{ Bronquiolite $0-4$} \\
\hline Precipitação & 0,99 & 0,0004 & $<0,001$ & 0,997 & 0,999 & - & - & - & - & - \\
\hline Amplitude & 0,76 & 0,0470 & $<0,001$ & 0,670 & 0,860 & 0,81 & 0,081 & 0,03 & 0,660 & 0,980 \\
\hline
\end{tabular}

Previsões para o modelo ARIMA $(0,1,2)(2,0,2)[12]$

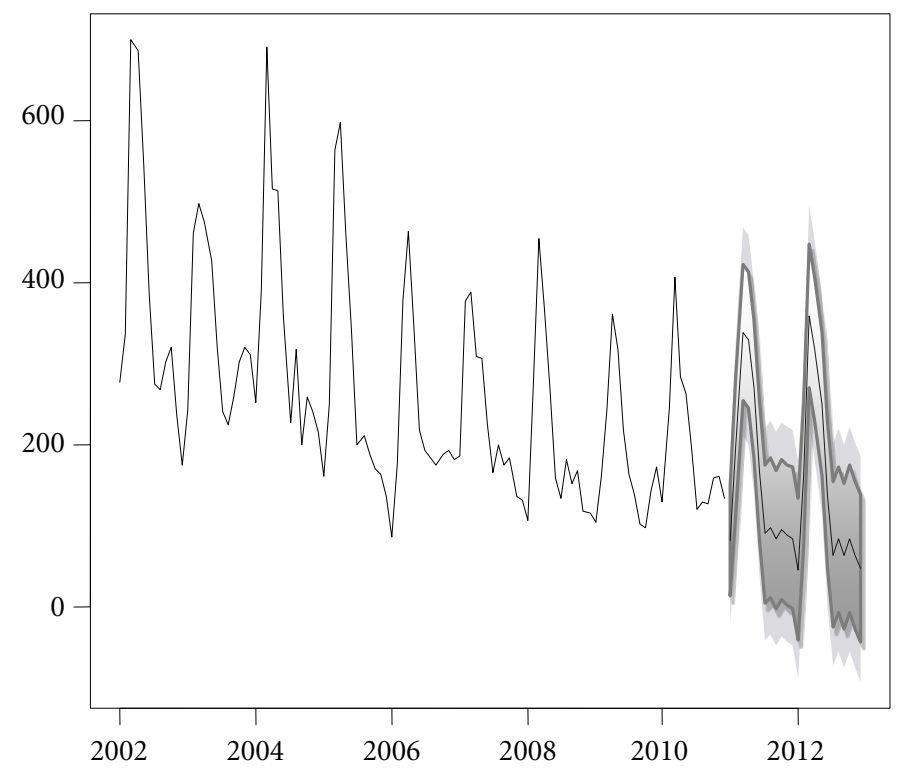

Figura 1. Modelo preditivo para o número de hospitalizações por asma de 0-14 anos em BH.

\section{Discussão}

O clima exerce importante papel em diversas doenças atópicas e infecciosas que estão entre as principais causas de morbidade e mortalidade em países em desenvolvimento, afetando princi- palmente as crianças. Neste estudo, avaliando o efeito climático por período de 11 anos, considerando temperaturas máxima e mínima, umidade relativa e precipitação acumulada, verificou-se: (1) a taxa de hospitalização por asma é maior na faixa etária de 0 -4 anos, no sexo masculino 
e vem apresentando queda no período do estudo. Em contraposição, a taxa de hospitalização por IVTRI (visto pela taxa de hospitalização por bronquiolite), entre crianças de $0-4$ anos, vem aumentando no mesmo período; (2) o número médio de hospitalizações por asma foi maior nos meses de março, abril e maio e, para a bronquiolite, nos meses de maio, junho e julho; (3) os modelos de regressão de Poisson mostraram que a redução da precipitação e o aumento da umidade relativa estão associados (a 5\% de significância) com o aumento das taxas de hospitalizações por asma e que a redução da temperatura máxima e precipitação estão associadas com as taxas de hospitalizações por IVTRI, incluindo seus efeitos em longo prazo; (4) por fim, o modelo preditivo demonstra a sazonalidade do evento e o comportamento histórico da redução do número de hospitalização por asma nas crianças e adolescentes em BH para os próximos anos.

Em Belo Horizonte, a asma é a segunda causa mais comum de hospitalização de crianças menores de 14 anos. Em estudo realizado de 1997 a 2000, já havia sido observado altas taxas de hospitalizações por asma com tendências descendentes em crianças menores de cinco anos ${ }^{20}$. De acordo com outro estudo, a redução das taxas de hospitalizações se manteve no período subsequente, de 2002 a 2012, sugerindo que ações do setor saúde e de outras origens podem estar impactando na queda das hospitalizações deste agravo na cidade ${ }^{6}$.

Entretanto, vale ressaltar que, apesar da queda das hospitalizações, o número ainda é elevado em comparação a países desenvolvidos ${ }^{21,22}$, induzindo a pensar que outros fatores podem estar concorrendo para a ocorrência do evento.

Outro achado interessante deste estudo é o incremento das hospitalizações por bronquiolite nessa mesma série histórica de 11 anos. Esta observação corrobora com os estudos que demonstram o aumento da circulação de múltiplos vírus nos últimos anos, afetando principalmente a saúde das crianças ${ }^{23}$. Sabe-se da importância da influência das condições meteorológicas propiciando a multiplicação e manutenção dos múltiplos vírus respiratórios no contexto urbano.

Entretanto, o ônus da condição meteorológica é geralmente subestimado pelas dificuldades da avaliação da exposição das variáveis meteorológicas no nível do indivíduo e pela negligência de informações nas anamneses, dificultando a mensuração dose-resposta. Conhecer a influência das variáveis meteorológicas e os períodos estimados de epidemia da asma grave, marcada por hospitalizações, possibilita intensificar a qualidade da atenção hospitalar e fortalecer os programas de promoção e controle desta enfermidade na atenção primária à saúde.

Alguns estudos têm mostrado a relação entre a variação sazonal e as proporções de ocorrência de asma no Brasil ${ }^{12,14,24,25}$, mas poucos tratam das hospitalizações por asma ${ }^{26}$. Ainda, nem todos os estudos chegaram às mesmas conclusões a respeito do papel das variáveis climáticas nas exacerbações respiratórias.

No presente estudo, observou-se a associação do aumento da umidade relativa, após o período de chuvas, nas hospitalizações por asma, incluindo seu efeito em longo prazo. Em geral, a umidade relativa indica o grau de saturação do ar e é fortemente influenciada pela precipitação pluviométrica. Entretanto, nesta pesquisa, as hospitalizações por asma se associaram à alta umidade e às baixas precipitações sugerindo, que efeitos tardios da chuva podem favorecer o aumento da umidade, outdoor e indoor ${ }^{26}$. A menor exposição ao sol e menor arejamento dos espaços domiciliares, com consequente crescimento de mofo e fungos, são fatores sabidamente contribuintes para o aumento das doenças respiratórias.

O município de Belo Horizonte representa a maior concentração urbana do estado de Minas Gerais. Por ser uma grande metrópole com ritmo de crescimento acelerado, propiciou a ocupação desordenada, inclusive das encostas inclinadas ou beira de córregos, principalmente por populações de baixa renda, determinando as áreas de riscos. Degradação ambiental, pobreza e extrema condição de risco geológico podem estar contribuindo para o aumento do alagamento dos solos, favorecendo o aumento da umidade intradomiciliar. Esse fato vai de encontro ao estudo que constatou maior concentração das hospitalizações por asma em áreas mais vulneráveis da cidade, denominadas de vilas e favelas ${ }^{6}$.

Pesquisas realizadas em outros estados brasileiros confirmam a influência da umidade nas doenças respiratórias em áreas de clima tropical, onde a mudança sazonal da temperatura durante $o$ ano não é de grande magnitude ${ }^{14,24,25}$.

Vale ressaltar que nos meses de chuva, em contraposição à problemática vivenciada nos meses de seca, a alta umidade relativa do ar aliada ao maior tempo de permanência das pessoas nos ambientes internos propicia que as pessoas estejam mais em contato com os alérgenos intradomiciliares, além do aumento do risco de disseminação viral entre as pessoas ${ }^{8,27,28}$. Como o estudo trata de hospitalizações, ou seja, casos graves 
de asma, a exposição por períodos prolongados a alérgenos intradomiciliares pode ter influenciando, por períodos mais longos (um e dois meses), a ocorrência dessas hospitalizações.

Quanto à influência das infecções virais do trato respiratório inferior (IVTRI) representado pelas hospitalizações por bronquiolite nas hospitalizações por asma, ambas na faixa etária de 0-4 anos, apesar de significativa (a 5\% de significância) a correlação encontrada foi numericamente pequena $(\mathrm{r}=30, \mathrm{p}<0,01)$, sugerindo que as IVTRI parecem ter pequena contribuição para o disparo da asma grave em $\mathrm{BH}$ uma vez que, não só os períodos epidêmicos foram distintos, mas também outras condições climáticas se associaram às taxas de hospitalização por esta causa.

Os resultados desse estudo mostram que o comportamento das hospitalizações por bronquiolite e por asma são diferentes, sendo a hospitalização por bronquiolite significativamente associada, no modelo de regressão de Poisson, à queda da temperatura máxima e a uma menor quantidade de chuvas na cidade, ou seja, coincidente com padrão do inverno na cidade. Neste período, autores têm demonstrado que a inalação de ar frio produz diminuição da temperatura na via aérea inferior, favorecendo a replicação do rinovírus ${ }^{29} \mathrm{e}$, a isto se soma o comportamento das pessoas nesse mesmo período, favorecendo a aglomeração e facilitando a transmissão viral, principalmente nas escolas, creches e residências ${ }^{8,28}$.

Outra contribuição do presente estudo foi a criação do modelo de séries temporais capaz de predizer, com boa precisão, futuros períodos epidêmicos das hospitalizações por asma na cidade, sendo isso de extrema relevância para a saúde pública. A Organização Mundial de Saúde (OMS) estimula a criação de modelos que possam prever aumento de doenças, pois poderão ser de valor incalculável para o combate e a prevenção de epidemias $^{30}$.

Este estudo apresenta avanços na compreensão da asma, mas também apresenta limitações que merecem ser consideradas, apesar de não comprometerem os achados da pesquisa conforme descrições.

Não foi possível avaliar o papel da concentração dos poluentes. Em Belo Horizonte, a qualidade do ar é determinada principalmente pelo tráfego veicular, já que as indústrias estão localizadas, em sua maioria, nas regiões metropolitanas e o uso de aquecedores a gás, pela população, é limitado. Os poluentes exercem efeito tóxico não só para pessoas sabidamente alérgicas, mas também pelo seu possível efeito em pessoas suscetíveis ${ }^{31,32}$.
Segundo a Fundação Estadual do Meio Ambiente $(\text { FEAM })^{33}$, a concentração dos poluentes atmosféricos na cidade está dentro dos limites permitidos em lei. Entretanto, não se deve desconsiderar o efeito dos mesmos em futuros estudos.

Sabe-se que a precipitação tem a capacidade de dissipar os poluentes, promover a remoção do ar impuro e retirar uma parcela significativa de materiais particulados suspensos, além de incorporar água da chuva. Além disso, o solo úmido evita a resuspensão das partículas para a atmosfera. No presente estudo a ocorrência do evento foi maior no período de baixa precipitação diminuindo assim seus efeitos benéficos na diminuição da concentração de poluentes.

Somando a isso, os ventos dificultam esta dispersão quando há aumento da rugosidade da superfície. Assim, cidades que apresentam tipografia mais heterogênea podem sofrer a influência da diminuição da velocidade e, decorrentemente, dificuldade da dispersão destes poluentes e, até mesmo, do calor.

O presente estudo também não avaliou a influência da insolação na ocorrência das hospitalizações, para testar condição contrária ao aumento da umidade. Entretanto, por estar altamente correlacionado com a temperatura máxima, o estudo optou por utilizar a temperatura como um possível proxy desta variável, o que não demonstrou correção entre as variáveis.

Outra limitação refere-se à utilização de dados secundados de hospitalização por asma e bronquiolite, sem confirmação diagnóstica em ambos e sem detecção do tipo viral da bronquiolite. A dificuldade, principalmente em crianças abaixo de 2 anos, da diferenciação diagnóstica de asma com doenças viróticas é sabida, principalmente por apresentarem características clínicas comuns. Entretanto, é importante salientar que a ocorrência da bronquiolite viral, que gera a hospitalização, é aguda e seu diagnóstico é eminentemente clínico, podendo ter evolução de sinais e sintomas diferentes da asma e tratamento diferenciado principalmente quanto à resposta ao uso do beta agonista. Ainda, a asma, em menores de 4 anos, teve um comportamento parecido com o das crianças de 10 a 14 anos. Porém estes achados não descartam erro diagnóstico.

Vale ressaltar que as informações dos Sistemas de Informação em Saúde do Sistema Único de Saúde Brasileiro e, em especial do Sistema de Informação Hospitalar (SIH-SUS) vem apresentando melhoria na qualidade dos dados ao longo do tempo e alta concordância com o Código Internacional de Doenças (CID). Estudos nesta área 
consideram que a utilização do SIH-SUS é valiosa para as análises epidemiológicas, devendo ser estimulada sua utilização, ainda modesta frente à potencialidade do sistema, sendo que ampla divulgação dos resultados pode estimular ao uso deste sistema ${ }^{34}$. A divulgação destes estudos é importante também para que os gestores dos sistemas tomem conhecimento dos resultados alcançados, podendo sugerir onde devem ser priorizados os esforços para o aprimoramento da qualidade dos dados e destacar as melhorias alcançadas com os esforços realizados. Os resultados do presente estudo foram ao encontro dos conhecimentos atuais, reforçando a consistência das informações.

Por fim, a inclusão de apenas hospitalizações públicas no estudo implica que uma parte da população foi excluída das análises. No entanto, de acordo com o Inquérito Nacional de Saúde de $2013,2 / 3$ da população brasileira foi admitida em hospitais públicos, especialmente pessoas com idade inferior a 17 anos $^{35}$, portanto, o estudo foi capaz de inferir suas descobertas para uma parcela expressiva da população.

Embora estes resultados devam ser interpretados com cautela devido às suas características metodológicas e limitações, eles podem promo- ver importantes informações no campo da saúde pública com implicações nas políticas em saúde, sociais e ambientais.

\section{Conclusão}

O clima exerce importante papel em diversas doenças respiratórias afetando principalmente a condição de saúde das crianças. Conhecer a influência das variáveis meteorológicas e os períodos estimados de epidemia da asma grave, marcada por hospitalizações, possibilita intensificar a qualidade da atenção hospitalar e fortalecer os programas de promoção e controle desta enfermidade na atenção primária à saúde.

Intervenções preventivas, como educação, correta abordagem dos sinais e sintomas, e monitoramento de casos graves em períodos epidêmicos; combinadas com intervenções em saúde, como acesso a medicamento a tempo, e Fisioterapia Respiratória; e juntamente com outras intervenções, como controle ambiental da residência e de seu entorno, e melhoria da condição social; são estratégias que poderão impactar na redução das crises e, consequentemente, das hospitalizações.

\section{Colaboradores}

CS Dias participou de todos os processos da escrita do artigo, incluindo organização do banco de dados e análises estatística. SA Mingoti participou da estruturação dos modelos estatísticos e análises. MAS Dias participou da elaboração da metodologia e contribuição na escrita do artigo. APR Ceollin participou da análise estatística e contribuiu na escrita do artigo. AAL Friche participou da elaboração da metodologia e contribuição na escrita do artigo. WT Caiaffa participou na elaboração da metodologia, nas análises estatísticas e redação do artigo. 


\section{Agradecimentos}

A $1^{\text {a }}$ fase do projeto BH-Viva (criação do Armazém de Dados e estudo qualitativo I) foi parcialmente financiada pelo Termo de Cooperação Observatório BH-Rio da Fiocruz; Vice-Presidência de Ambiente, Atenção e Promoção da Saúde (VPAAPS); e Universidade Federal de Minas Gerais, Observatório de Saúde Urbana de Belo Horizonte (UFMG-OSUBH), no âmbito do QUALISUS, em 2011-12 e projetos FAPEMIG. A 2a fase (inquérito e estudo qualitativo II) pelo Ministério da Saúde (Fundo Nacional de Saúde) por meio da Fundação Oswaldo Cruz (Fiocruz). Os autores gostariam também de agradecer à equipe do Observatório de Saúde Urbana de Belo Horizonte da Faculdade de Medicina da Universidade Federal de Minas Gerais (OSUBH-FM-UFMG), à inestimável equipe de urbanistas da Companhia Urbanizadora de Belo Horizonte (URBEL) e ao Conselho Nacional de Desenvolvimento Científico e Tecnológico (CNPq), pelas bolsas de produtividade em pesquisa (WTC e AALM).

\section{Referências}

1. Global Initiative for Asthma (GINA) [página na Internet]. Disponível em: http://www.ginasthma.org

2. Kopel LS, Phipatanakul W, Gaffin JM. Social disadvantage and asthma control in children. Paediatr Respir Rev 2014; 15(3):256-263.

3. Brasil. Ministério da Saúde (MS). DATASUS - Sistema Nacional de Dados 1993-2010 [página na Internet]. Disponível em: www.datasus.gov.br

4. Moura BLA, Cunha RC, Aquino R, Medina MG, Mota ELA, Macinko J, Dourado I. The main causes of hospitalization for primary health care sensitive conditions in Brazil: an analysis by age groups and region. Rev Bras Saude Matern Infant 2010; 10(Supl. 1):S83-S91.

5. Bastos RM, Campos SEM, Ribeiro LC, Bastos-Filho MG, Teixeira MTB. Hospitalizations for ambulatory care-sensitive conditions, Minas Gerais, Southeastern Brazil, 2000 and 2010. Rev Saude Publica 2010; 48(6):958-967.

6. Dias CS, Dias MAS, Friche AAL, Almeida MCM, Viana TC, Mingoti SA, Caiaffa WT. Temporal and spatial trends in childhood asthma-related hospitalizations in Belo Horizonte, Minas Gerais, Brazil and their association with social vulnerability. Int J Environ Res Pub Health 2016; 13(7):704.

7. Wang W. Progress in the impact of polluted meteorological conditions on the incidence of asthma. J Thorac Dis 2016; 8(1):E57-E61.

8. Johnston NW, Johnston SL, Norman GR, Dai J, Sears MR. The september epidemic of asthma hospitalization: school children as disease vectors. J Allergy Clin Immunol 2006; 117(3):557-562.

9. Silva ECF. Alergia respiratória. Rev Hospital Univer Pedro Ernesto UERJ 2008; 7(2):33-57.

10. O'Connor GT, Neas L, Vaughn B, Kattan M, Mitchell H, Crain EF, Evans R 3rd, Gruchalla R, Morgan W, Stout J, Adams GK, Lippmann M. Acute respiratory health effects of air pollution on children with asthma in US inner cities. J Allergy Clin Immunol 2008; 121(5):1133-1139.

11. Grech V, Balzan M, Asciak RP, Buhagiar A. Seasonal variations in hospital admissions for asthma in Malta. J Asthma 2002; 39(3):263-268.

12. Silva Júnior JLR, Padilha TF, Rezende JE, Rabelo ECA, Ferreira ACG, Rabahi MF. Efeito da sazonalidade climática na ocorrência de sintomas respiratórios em uma cidade de clima tropical. J Bras Pneumol 2011; 37(6):759-767.

13. Nielsen KG, Bisgaard H. Lung function response to cold air challenge in asthmatic and healthy children of 2-5 years of age. Am J Respir Crit Care Med 2000; 161(6):1805-1809.

14. Valença LM, Restivo PCN, Nunes MS. Variação sazonal de atendimento de emergência por asma em Gama, Distrito Federal. J Bras Pneumol 2006; 32(3):284-289.

15. Weiland SK, Husing A, Strachan DP, Rzehak P, Pearce N, ISAAC Phase One Study Group. Climate and prevalence symptons of asthma, allergic rhinitis, and atopic eczema in children. Occup Environ Med 2004; 61(7):609-615. 
16. Instituto Brasileiro de Geografia e Estatística (IBGE). Censo de 2010 [página na Internet]. Disponível em: http://censo2010.ibge.gov.br/

17. Friche AAL, Dias MAS, Reis PBR, Dias CS, Caiaffa WT. Urban requalification interventions and the impact on health: Study protocol "quasi-experimental" with mixed methods-BH-Project Viva. Cad Saude Publica 2015; 31(Supl. 1):S1-S14.

18. TempoClima PUC Minas [página na Internet]. Disponível em: http://www.pucminastempoclima.com. br/

19. Morettin PB, Toloi CMC. Análise de Séries Temporais. $2^{\mathrm{a}}$ ed. São Paulo: ABE- Projeto Fisher e Editora Edgard Blucher; 2006.

20. Dias MAS, Caiaffa WT, Machado-Coelho GLLM. Poverty is associated with asthma hospitalization and re-hospitalization rates, 1997-2000: An ecological analysis in Belo Horizonte City, Brazil. J Urban Health 2003; 80:ii108-ii109.

21. Largent J, Nickerson B, Cooper D, Delfino RJ. Paediatric asthma hospital utilization varies by demographic factors and area socio-economic status. Public Health 2012; 126(11):928-936.

22. Brozekm G, Lawson J, Shpakou A, Fedortsiv O, Hryshchuk L, Rennie D, Zejda J. Childhood asthma prevalence and risk factors in three Eastern European countries: the Belarus, Ukraine, Poland Asthma Study (BUPAS): an international prevalence study. BMC Pulm Med 2016; 16:11.

23. Costa LDC, Costa PS, Camargos PAM. Exacerbation of asthma and airway infection:is the virus the villain? J Pediatr 2014; 90(6):542-555.

24. Façanha MC, Pinheiro AC. Distribution of acute respiratory diseases in Brazil from 1996 to 2001, Brazil. Rev Saude Publica 2004; 38(3):346-350.

25. Rosa AM, Ignotti E, Botelho C, Castro HA, Hacon SS. Respiratory disease and climatic seasonality in children under 15 years old in a town in the Brazilian Amazon. J Pediatr 2008; 84(6):543-549.

26. Saldanha CT, Silva AMC, Botelho C. Variações climáticas e uso de serviços de saúde em crianças asmáticas menores de cinco anos de idade: um estudo ecológico. J Bras Pneumol 2005; 31(6):492-498.

27. Jaakkola JJK, Hwang BF, Jaakkola N. Home dampness and molds, parental atopy, and asthma in childhood: a six-year population-based cohort study. Environ Health Perspect 2005; 113(3):357-361.
28. Nesti MM, Goldbaum M. Infectious diseases and daycare and preschool education. J Pediatr 2007; 83(4):299-312.

29. Jartti T, Lee W-M, Pappas T, Evans M, Lemanske Jr, RF, Gern JE. Serial viral infections in infants with recurrent respiratory illnesses. Eur Respir J 2008; 32(2):314-320.

30. World Health Organization (WHO). Global Partnership to Roll Back Malaria. Using climate to predict infectious disease outbreaks: a review. Genebra: WHO; 2004.

31. Tramuto F, Cusimano R, Cerame G, Vultaggio M, Calamusa G, Maida CM, Vitale F. Urban air pollution and emergency room admissions for respiratory symptoms: a case-crossover study in Palermo, Italy. Environ Health 2011; 10:31.

32. Gasana J, Dillikar D, Mendy A, Forno E, Vieira ER. Motor vehicle air pollution and asthma in children: a meta-analysis. Environ Res 2012; 117:36-45.

33. Fundação Estadual do Meio Ambiente (FEAM). Relatório técnico: monitoramento da qualidade do ar na região metropolitana de Belo Horizonte no ano base de 2011. Belo Horizonte: FEAM; 2013.

34. Lima CRA, Schramm JMA, Coeli CM, Silva MEM. Revisão das dimensões de qualidade dos dados e métodos aplicados na avaliação dos sistemas de informação em saúde. Cad Saude Publica 2009; 25(10):2095-2109.

35. Instituto Brasileiro de Geografia e Estatística (IBGE). Pesquisa Nacional de Saúde 2013 [documento na Internet]. Rio de Janeiro: IBGE; 2014. Disponível em: ftp://ftp.ibge.gov.br/PNS/2013/pns2013.pdf.

Artigo apresentado em 24/04/2017

Aprovado em 09/05/2019

Versão final apresentada em 11/05/2019 